looking man. He had ptosis and external strabismus of the right eye, in which there was also the scar remaining from the cataract extraction. The right great toe was swollen and red, and on its plantar surface, over the position of the articulation between the phalanges, was a sloughy ulcer, three-quarters of an inch in diameter. The edges of this ulcer were sharply cut, the discharge fetid. Movement of the joint produced grating, and a probe impinged on bone and entered the joint, but did not cause much pain. There was no loss of cutaneous sensation. The left knee, which was considerably enlarged, presented a large fluctuating swelling. It extended upwards in the position of the synoval cavity of the knee-joint and for some inches down the tibia. The circumference of the knee was nineteen and three-quarter inches, and from above downwards it measured eleven inches. In the upper part its colour was that of normal integument with dilated veins over it; below it was reddened and the skin thinned, and it appeared to lay over the tibia. The patella was superficial, widened and greatly enlarged, below and to its inner side could be felt a bony plate. The movements were too free (flail-like) and attended with rough grating. There was little pain or tenderness. The temperature of the joint was higher than on the opposite side. The little finger of the right hand was contracted; attempts to straighten it made tense a cord-like structure which extended into the palm, but not beyond the annular ligament. The ring and middle fingers were also contracted, but to a less extent. A similar contraction, though to a less degree, was visible in the little finger of the left hand. The right pupil was irregular from former operation; neither pupil reacted to light nor to accommodation. The movements of the eyes, though slow, were well performed; vision was defective. There was no wasting of the muscles, but coördination was imperfect. Patellar reflex was absent. There was some incontinence of urine and decided loss of sexual power, but neither for more than three weeks. The temperature was $100 \cdot 6^{\circ}$. There was no albuminuria. He was kept in bed, the leg being placed between sand-bags and an ice-bag applied to the joint.

Feb. 3rd.-The swelling appeared larger, bagging below the knee, the skin over its lower part being very red and shiny; the redness of the skin was limited to the lower part and did not extend to the rest of the knee. The femur was displaced forwards and outwards, the tibia being drawn backwards and inwards.

5th.-Four ounces of sanious pus removed by the aspirator, the puncture being made over the outer side of the joint.

7th.-The swelling of the joint had diminished, and there was less redness. A large bony outgrowth could be felt extending across the front of the joint below the patella.

13th.--An incision was made into the toe of the left foot and pus evacuated.

16th.-The skin had much thinned over the joint in two places, below and to the outer side.

17th.-These portions of skin gave way, and a semi-transparent fluid began to ooze from them. A poroplastic splint was applied to the foot on which the ulcer existed.

26th.-The discharge has continued, and now the swelling is almost limited to the knee. The openings are dressed with carbolic oil.

March 10th.-The larger opening was increased by incision, and a probe passed backwards was found to enter the kneejoint.

16th.-There was brisk plantar reflex in both legs, the sensation being, however, delayed in each, especially in the left, where as much as six seconds intervened between the application of the stimulus and its appreciation by the patient. In the afternoon the patient was placed under ether, and Mr. Croft amputated the thigh in the lower third by anterior and posterior flaps. The latter was cut from within outwards, but the knife encountered a long bony outgrowth, which extended from the joint for a long distance upwards in the body of the semi-membranosus muscle, which had to be divided by the saw. The femur was dense and ivory-like. The fasciæ appeared thickened and the muscles coarse. The arteries were rigid and atheromatous. The operation was performed with antiseptic precautions.

Until Feb. 4th, when the joint was aspirated, the temperature did not fall below $99^{\circ}$ in the morning, and usually rose to $101^{\circ}$ and on more than one occasion to $103^{\circ}$ in the evening. After this it was better, not rising above $99 \cdot 6^{\circ}$ until the 10th, when the small incision was made. It was then somewhat irregular again. After the operation he had a good deal of pain in the stump, and the temperature rose to $105^{\circ}$, falling later in the day to $101^{\circ}$.

27th.--Progress has been quite satisfactory. The stums was dressed again; all the sutures and the drainage-tubes were removed. The wound is healing well. The temperature has been about one degree higher in the evening than in the morning, $99 \cdot 2^{\circ}$ to $1002^{\circ}$.

30th.-The patient having been placed under ether, the head of the proximal phalanx of the right great toe was removed, and the base of the distal phalanx scraped. The wound was plugged with iodoform gauze and dressed antiseptically.

April 10th (twenty-fifth day).-Violent hæmorrhage from the thigh came on at night. The inner extremity of the primary incision was extended upwards, and the femoral artery secured by silk ligatures in Hunter's canal; it was divided between the ligatures. A short time before the hæmorrhage the temperature rose to $103^{\circ}$, having been only $95^{\circ}$ two hours before.

11th.--The patient was weak and suffering somewhat from shock. Pulse 90 , feeble; temperature $978^{\circ}$. The stump was dressed with iodoform. The patient from this date gradually recovered, but continued weak for some days. On the 26th an abscess which had been forming over the sacrum was opened, and after this had been incised the temperature, which had been irregular in character, became normal.

29th.-The abscess was healing. He took food well, Tongue slightly furred; bowels regular. Pulse 79, feeble temperature normal. At 8 P.M. there was some hæmornhage from the stump, but very little blood was lost, as the flow was immediately arrested. An incision was made at the apex of Scarpa's triangle, and the femoral ligatured with thick catgut (nineteen days after the last hæmorrhage and forty-four since amputation of the thigh).

From this time the patient made slow but satisfactory progress towards recovery. The wounds all suppurated, but not freely, and were very slow in healing. The wound of the foot and the abscess in the hand healed well before he left; and the temperature was normal for the last two months of his residence in the hospital, with the exception of May 1st, 18th, and 19th, when it reached $1002^{\circ}, 1006^{\circ}$, and $1002^{\circ}$ respectively.

On examination of the removed joint, it showed wellmarked disease, described as characteristic of Charcot's disease of the joint. But there was also an unusual number of bony growths around it; one divided at the time of operation extended for about nine inches up the thigh, and was as thick as the little finger.

\section{MONTGOMERYSHIRE INEIRMARY.}

COMPOUND COMMINUTED AND DEPRESSED FRACTCRE OF SKULL.

(Under the care of Mr. C. E. Monno.)

THex following case is worthy of record, especially in riew of the almost complete absence of cerebral symptoms proper, although the lesion was a severe one.

R. G-, a stout, healthy, and steady agricultural labourer, in his twenty-first year, presented limself at Mr. Monros surgery on June 18th with a severe wound over the left side of the frontal bone, about an inch above the orbit. He stated that whilst letting a horse loose in a field he was kicked by the horse with his hind legs, the tip of the shoe striking him on the forehead. On examination, there was found a large fragment. of bone depressed and partially pushed up behind the edge of the frontal bone, above, there were several loose fragments. The wound was about two inches and a half in length. Strange to say, the patient was not even stunned, but got upon his feet after being knocked down, walked about 300 yards to his master's house, and rode into Newtown, a distance of orer a mile. From the severity of the case, and the necessity of immediate operative interference, the patient was sent to the Montgomeryshire Infirmary.

Soon after admission chloroform was administered br $\mathrm{H}$ J. H. Harris. The patient at the time was suffering slightlr from shock. Pulse on admission 48; after chloroform 60 ; no vomiting. Pupils equal. He was quite coherent. dir from the frontal sinuses, with blood, bubbled out of the inner aspect of the wound. One large fragment of bone 
Fas removed by the elevator and forceps, measuring $1 \frac{1}{4} \mathrm{in}$. in length by $\frac{11}{16} \mathrm{in}$. wide, together with five smaller fragments. The brain could be seen pulsating at the bottom of the wound, and a portion of brain exposed corresponding to the dimensions of the larger fragment of bone removed. Dura mater not divided; two sutures and drainage-tube introduced; ends of wound left open. Five grains of subchloride of mercury were administered, and an ounce of compound senna mixture.

June 19th.-11 A.M.: Pulse 76; temperature 98. $7^{\circ}$. During the night the bowels acted three times; patient quiet, not complaining of much pain ; tongue clean; feels sick ; pupils respond readily to light; is thoroughly conscious, and answers questions readily and without hesitation; in fact there is a singular absence of brain symptoms.-11 P.M.: Pulse 68; temperature $98^{\circ}$. Is somewhat restless; cormplains of feeling general headache; breathing quiet, now and then inclined to be slightly stertorous. Ice-cap obtained, and ice and powdered salt applied to the head.

20th--Noon: Pulse 68; temperature 98. $8^{\circ}$. Head cool no marked cerebral symptoms, excepting somewhat slow pulse; still feels sick. Wound quite healthy.-7.30 P.M. Pulse 66 ; temperature $984^{\circ}$. Complains of pain.

21st - Pulse 62; temperature $99^{\circ}$. Passed a restless night on account of pain. To have fifteen grains of chloral hydrate and fifteen grains of bromide of potassium every five or six hours.-9.30 P.M.: Pulse 58; temperature normal. Tongue dean; has taken very light liquid nourishment well during the day; has had several severe attacks of paroxysmal pain of neuralgic character, but relieved by the medicine; no local tenderness.

22nd-10 A.M.: Pulse 62; temperature 99 . IIas passed a restless night; tongue clean; has had several severe paroxysms of pain. There is no symptom of compression or any functional disturbance of brain. Drainage-tube removed; wound dressed with boracic acid lotion. Bowels hare not acted to-day. To take two ounces of white mixture-Evening: Pulse 64, good; temperature $98^{\circ}$; is restless; still complains of pain (paroxysmal); tongue clean. 23rd.-11 A.M.: Pulse 62; temperature $98 \cdot 6^{\circ}$. Still complains of severe pain of a neuralgic character, occurring at intervals, and not now apparently relieved by the chloral hydrate and bromide. Ordered hydrate of croton chloral with gelsemium and monobromide of camphor. Sutures were removed, and wound strapped with salicylated isinglass plaster; this seemed to cause uneasiness, and was removed in the evening. -4 P.M. : Pain intense. Matron states that the patient has been at times delirious, but not so at the time of visit. Pulse 66 , of good volume; temperature $99 \cdot 4^{\circ}$ pupils equally contracted, but sluggish. To have an enema, as the morning aperient has not acted. Head to be shaved, and leeches to be applied should the temperature continue to rise, with increase of pain and delirium.-10 P.M.: Pulse 50 temperature $94^{\circ}$. Patient is not in so much pain; pupils not now contracted, but sluggish; bowels have acted freely is not so restless, but rather drowsy.

24th,-7.30 P.M.: Pulse 55; temperature 98.5०. Patient such better; very little pain to-day; passed a quiet night; wound bealthy.

20th--Pulse 50; temperature normal. Very little pain ; wound almost healed; slept well last night; pupils equal, respond well to light; tongue clean ; appetite good; bowels acting well.

From this time the patient rapidly improved, occasionally suffering slight pain. In view of the statement that the conrolutions of this portion of the frontal lobe were the seat of perception of colour, Mr. Monro carefully tested the patient, and found that his perception of colour was quite normal. On the 29 th he was allowed to rise and to have a little solid food. The wound had quite healed. On July 15 th he was discharged quite well, with a caution not to go to work for a month, and then not in a hot sun.

A LOCAL BOARD FOR GRAYS. - For some time past the question of the formation of a local board has been sgitated at Grays. A poll has just beon held, and has reinlted in a majority of 278 for the establishment of a board. The Local Government Board have recently been paying furticular attention to the whole of this district on both sides of the river, and there is little doubt that a complete drainage system will be insisted upon, especially in rifw of the vast increase of house property consequent upon the construction of the new docks at Tilbury.

\section{烈ledical Sorieties.}

\section{ACADEMY OF MEDICINE IN IRELAND.}

\section{Notes of Visits to Contrexéville and Royat.-Primary} Sarcoma of Right Kidney.

$\Delta \mathrm{T}$ the closing meeting of the Medical Section, held May 29th, 1885, Dr. Cruise, President, read a paper giving an account of his visits to Contrexéville and Royat-lesBains, with some details respecting these mineral waters, and pointing out the various cases in which they are found useful. The substance of this paper has already appeared in our columns. - The Chairman, Dr. DuFFer, noticed that the President did not allude to the silica in these springs.-. Dr. TichbonNe, having examined Contrexéville water, as imported, said the analysis was almost identical with that exhibited in the President's diagram, and therefore what found its way to this country was genuine. That was not always the case. It appeared from the analysis that chlorine was associated with iodide of potassium. But it was a difficult thing to prognosticate from an analysis what was the composition of the water, since chlorine was not originally associated with it. He was struck with the analysis of Royat water as regards the extraordinary amount of lithium-0.037, being about $2 \frac{1}{9}$ grs. per gallon. It was of great interest to see that the water was so rich in that particular body. He asked had sesium and rubidium been found, there being an idea that they possess qualities similar to lithia in their action.-Dr. JAMES LITTIE said he was not in a position to speak of the waters of Royat; but many years ago he had heard from Dr. Cruise of the value of the Contrexéville waters in affections of the bladder. That practical piece of information had helped him to keep persons alive with diseased bladders; and since then he had formed an opinion of these waters. Those to whom he gave the waters said they produced the effects Dr. Cruise had enumerated, and that they usually improved the appetite, kept the bowels open, and made people feel comfortable. In this country the waters appeared to be useful in that kind of dyspepsia occurring in people of a sallow complexion and sedentary habit connected with a diseased condition of the liver. In gall-stone the waters also appeared to be useful. An old London physician had told him that he gained more benefit from gout by the Contrexéville waters than any other mode of treatment. The chief virtue of the Contrexéville waters lay in their effect on the urinary organs, especially catarrh of the bladder and stone. In catarrh of the bladder he first had had an opportunity of seeing the value of the waters. It was the case of an old man in whom catarrh had arisen in connexion with imperfect emptying of the bladder through enlarged prostate. From a physician whom he met at Contrexérille, he ascertained that in giving the water for stone the best plan was to give a large quantity early in the morning before breakfast, whereas for catarrh or gout the better plan was to give it in divided portions during the day. To clear away gravel, he had recommended patients to drink a bottle before breakfast. But in catarrl of the bladder he had recommended a certain portion before breakfast, luncheon, and dinner. A few months ago he saw a lady, and, from the account she gave of the pain running down the thigh, he felt certain it was renal calculus He recommended her a six weeks' course, and at the end of that time he received from her the calculus diagnosed. With regard to Contrexéville itself, as compared with the great German baths, it was rather a sad place.-Dr. H. KENNEDY approved highly of Dr. Cruise's remarks. But a large number of persons were unable to visit those baths, and it was, then, well to keep in mind the work of Roberts of Manchester, in which, by medical treatment alone, he proved that not only could calculus in the bladder be modified, but even be brought away.-Dr. Finny had employed Contrexéville water in some cases of bladder affections where cystitis was a common symptom; but his experience was not so good as that of those who had spoken; in fact, he was disappointed in the results. He did not find that it gave relief to the bladder troubles, nor that it improved the condition of the water in removing the mucus, as Dr. Cruise had experienced. But perhays in this country the habits of the patient, combined with the climate and other 